presumably to have these patterns relabelled and responded to as 'depression'. However, those of our respondents $(n=31)$ who did label our 'severe mental illness' vignette as 'depression' were more likely to offer stigmatising responses to the vignette than the other respondents on 14 of our measures of stigmatisation, with less stigmatising conceptions on only nine (and one equal).

What other lay categories overlap with 'depression'? And how? Is the term used in similar ways for what we (as psychiatrists) would term dysthymia and clinical disease? What is its semantic network, those other meanings which it connotes and evokes? (Kleinman \& Good, 1985). Does 'depression' entail characteristic patterns of personal responsibility and attribution? What is the logical structure of the elicited ideas? How stable, how contingent are they? We are not necessarily arguing for a proper ethnographic study (although the effort which is to be put into the educational campaign might warrant this). There are avallable a number of rigorous ethnographically-derived instruments such as the Explanatory Model Interview Catalogue (Weiss et al, 1992) which could have furnished precisely this information.

An extensive literature is available on popular illness categorisations and health-related behaviours - the subject matter of medical anthropology - including major conceptual studies on 'depression' (Kleinman \& Good, 1985). We are concerned that the College has placed so much conviction in a restricted public opinion survey in a way that might have seemed immediately plausible at the policy level, but which ignores the current evidence in favour of the sort of rather easier but practically limited attitudinal studies once popular in the United States. We are even more concerned that the College seems to recommend this as the appropriate way to go about research into categorisations of illness. To then mount a glossy educational campaign on the basis of this method is frankly disturbing; research in other public health domains such as leprosy shows that attempts to educate the public simply by inculcating professional medical models (supposedly 'less stigmatising' - and that is another question) do not necessarily bring about reduced stigmatisation or improved compliance (Weiss et al, 1992).

To understand those responses we term 'stigma', and how they function, we need to start from two different methodological approaches the biomedical and the ethnographic - without predicating the one on the other (Littlewood, 1990). Only then may some sort of meeting point emerge and help clinicians incorporate patients' own models of illness as relevant clinical information (Kleinman, 1987).

\section{References}

Holy, L. \& STUCHLIK, M. (1980) The Structure of Folk Models, London: Academic Press.

JADHAV. S.S. (1992) Adapting the EMIC to study depressed British subjects. Abstracts, XII World Congress of Soctal Psychiatry, New Delhi.

KLEINMAN, A. (1987) Anthropology and psychiatry: The role of culture in cross-cultural research on ilness. British Journal of Psychiatry, 161, 447-454.

- \& GoOD, B. (eds) (1985) Culture and Depression: Studies in the Anthropology and Cross-Cultural Psychiatry of Affect and Disorder. Berkeley: California University Press.

LTTTLEWOOD, R. (1990) From categories to contexts: a decade of the 'new cross-cultural psychiatry'. British Journal of Psychiatry, 156, 308-327.

ROYAL COLLEGE OF PSYCHIATRISTS (1992) Research study conducted for the 'Defeat of Depression' campalgn, ms: Royal College of Psychiatrists.

WeISS, M., DoongAJ, D. et al (1992) The explanatory model interview catalogue (EMIC): a contribution to crosscultural research methods from a study of leprosy and mental health. Brittsh Journal of Psychiatry, 160, 819830.

WHITE, G.M. (1982) The ethnographic study of cultural knowledge of 'mental disorder'. In Cultural Conceptions of Mental Health and Therapy (eds. G.M. White and A.J. Marsella) Dordrecht: Reidel.

Sushrut Jadhav, Lecturer, and Roland Littlewood, Professor, Centre for Medical Anthropology, Departments of Psychiatry and Anthropology. University College London, WC1E 6BT

\title{
Response from Professor R.G. Priest
}

Jadhav \& Littlewood make some interesting and thoughtful points, but I cannot agree with some of their syllogisms. I certainly do not sympathise with the pejorative tone of their comments ("to mount a glossy [sic] campaign ... is frankly disturbing") nor accept what appears to be their principal conclusion that "the proposed educational programme is premature". 
They outline in an articulate and informative way some of the disadvantages of surveys of the MORI. We could add a few more disadvantages to their list. However, I can reassure them that in my contact with the Royal College of Psychiatrists, I have not detected any hint of a suggestion from the College that its members believe that reliance on such surveys is "the appropriate way to go about research into categorisations of illness". Jadhav \& Littlewood are mistaken if they really believe that the campaign is mounted "on the basis of this method".

It might be helpful if I outline some of the facts that are fundamental to the campaign.

(a) Many persons in the community suffering from serious depressive illness do not at present seek help from their general practitioners (possibly $50 \%$ of those affected).

(b) Many patients with serious depressive illnesses consulting their GPs are not diagnosed as suffering from depression at the initial interview.

(c) Depressive illness is a treatable disorder.

(d) Much suffering would be saved if we could improve on the situation outlined in points (a) and (b).

I do not think that Jadhav \& Littlewood can dispute these facts. These are among those on which the Defeat Depression campaign is mounted. Indeed, at the press briefings to launch the various campaign initiatives, we were questioned about not having mounted the campaign earlier.

In the course of the campaign we hope to correct one impression, revealed in the MORI survey, that the vast majority of a representative sample of the population thought that antidepressants were addictive (a belief that would understandably contribute to poor compliance with treatment). In addition we hope to make doctors more aware of the benefits of nonpharmaceutical interventions such as cognitive therapy in depression. By emphasising the extent to which depression may be treated we hope that we will encourage patients to receive help, and enable relatives and friends to perceive the importance of getting appropriate treatment. This should help to overcome the current stigma attached to having a mental illness and seeking help.

If Jadhav \& Littlewood wish to know more details of the campaign they should consult the consensus statement (Paykel \& Priest, 1992) which gives a balanced view on the subject, and is supported by scientific references.

I am sure that readers of the Psychiatric Bulletin will be pleased to know that the campaign is progressing well. The educational video package produced for trainers in general practice (on the recognition and management of depression) has sold out. We have distributed more than two and a half million copies of the depression leaflet to members of the public. We have received a vast amount of coverage in the national and local media. Sympathetic and informative articles have appeared in medical journals. We had also sold out of the first print run of the Gaskell publication Down with Gloom within two months of publication.

I should like to use this opportunity to express my appreciation of all those who have laboured hard to make the campaign rewarding so far.

\section{Reference}

PAYKel. E.S. \& PRIEST, R.G. (1992) Recognition and management of depression in general practice: consensus statement. British Medical Journal, 305, 1198-1202.

R.G. Priest, Professor of Psychiatry, St Mary's Hospital Medical School, Praed Street, London W2 $1 N Y$

\section{Corrigendum}

In the article 'Mental Health Services in Cyprus' by Marios Pierides (Psychiatric Bulletin, July $1994,18,425-427$ ) the captions for Figs. 2 and 3 were transposed during printing. 